\title{
TRABALHANDO E APRENDENDO: ADQUIRINDO QUALIFICAÇÃO EM UMA INDÚSTRIA DE REFINO DE PETRÓLEO"
}

\author{
Vera LÚCia Bueno Fartes **
}

\begin{abstract}
RESUMO: O estudo de que trata o presente artigo tem seu foco na análise dos processos de aquisição da qualificação de trabalhadores num segmento da indústria - o complexo petróleo-petroquímica. Para isso, a pesquisa procura identificar os loci de aquisição da qualificação dos operadores de três unidades de processamento de petróleo, distintas entre si por suas idades tecnológicas e importância no processo produtivo do setor da Refinaria a que pertencem. Os resultados da pesquisa indicam que, embora as influências societais e os conhecimentos adquiridos no processo de escolarização geral e profissional sejam importantes fatores na aquisição da qualificação, o local de trabalho sobressai como instância principal na qualificação dos operadores de processo, independentemente da unidade investigada.
\end{abstract}

Palavras-chave: Educação. Processos de qualificação. Aquisição. Trabalhadores industriais.

\section{WORKING AND LEARNING: QUALIFICATION ACQUISITION IN A PETROLEUM REFINERY}

ABSTRACT: The present article consists of a study focused on the analysis of processes of qualification acquisition experienced by industrial workers in the field of petroleum -petrochemicals. This research identified the loci of qualification acquisition of operatives working in three distinct oil process units, which differ from the others in terms of technological advancement and importance

* O artigo, síntese de tese de doutoramento, orientada pela $\operatorname{Prof}^{\circ} \operatorname{Dr}^{\circ}$ Nadya A. Guimarães, resulta de pesquisa mais ampla, intitulada "Qualificação, mercados e processos de trabalho: Estudo comparativo no complexo químico brasileiro", coordenado pela mesma professora, como parte do Programa de Pesquisa em Ciência e Tecnologia, Qualificação e Produção. Cedes/Finep/PDCT-CNPq, São Paulo, 1998.

** Professora do Departamento de Educação I e do Programa de Pós-Graduação (mestrado e doutorado) da Faculdade de Educação da Universidade Federal da Bahia (UFBA). E-mail: verafartes@uol.com.br 
to the production process. A major finding of the study is that the place of work represents the main source of qualification for oil process operatives, independently of the unit investigated. Social milieu influences and knowledge acquired through school and professional education also proved to be important for the qualification process.

Key words: Education. Processes of qualification. Acquisition. Industrial workers.

\section{Introdução}

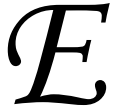

ste artigo tem por objetivo apresentar alguns achados de pesquisa recentemente concluída sobre as múltiplas dimensões da aquisição da qualificação de trabalhadores em uma indústria de refino de petróleo, cuja principal característica, em termos de organização do processo produtivo, é o chamado "processo contínuo", o que, de um modo geral, pode ser descrito como um processo produtivo em que ao operador cabe controlar reações físico-químicas não manuseando a matéria-prima e que, por isso mesmo, dele se exige um forte componente de abstração e de representação mental do processo de trabalho (Guimarães, 1987). A escolha pelo direcionamento do foco da qualificação para seus processos aquisitivos deveu-se ao fato de que há muito se vinha considerando a existência de uma dívida da linha temática de pesquisas sobre Trabalho e Educação para consigo mesma. Em outras palavras, sentiu-se a necessidade de uma apropriação pedagógica que pusesse em evidência a dimensão educacional dos estudos sobre qualificação.

Partindo dos princípios propostos por Dewey (1976) de que conhecimento e, portanto, aprendizagem e qualificação são processos multidimensionais e contínuos, e reconhecendo, com Drucker (1993), que se vive numa "sociedade do conhecimento", procurou-se nortear a pesquisa pelas indagações: Quando, onde e como os trabalhadores adquirem qualificação? Qual o peso da escola nesse processo? De que forma a família e o meio social em geral promovem a qualificação dos trabalhadores? Qual o papel dos cursos e treinamentos, hoje mais do que nunca, necessários à reatualização constante do saber, em face da velocidade das mudanças no conhecimento? Como os trabalhadores adquirem os chamados conhecimentos tácitos no cotidiano do trabalho?

Tendo em mente essas questões, orientou-se a pesquisa para a investigação sobre os processos de aquisição da qualificação, partindo do juízo amplamente aceito e difundido de que existe uma forte relação 
entre o contexto de reestruturação produtiva e os novos requisitos de qualificação, treinamento e formação do trabalhador, o que resultou na hipótese central do estudo, qual seja, a de que a aquisição $d a$ qualificação é um processo que resulta da inserção individual em distintos contextos socioinstitucionais, os quais podem ser melhor compreendidos quando se analisam as interações que os sujeitos constroem ao longo de sua trajetória de vida, seja nas experiências familiares, seja nas escolares, seja nas profissionais. O peso de tais experiências, todavia, é variável de acordo com a intensidade das mudanças tecnológicas e a modalidade de gestão e organização do trabalho.

\section{Dimensões conceituais e empíricas da aquisição da qualificação}

Tendo em vista a hipótese inicialmente formulada, tinha-se que definir e situar a base teórica que possibilitasse dar consistência ao seu enunciado, esclarecendo, em primeiro lugar, o que se entende por aquisição da qualificação. Escudando-se no pensamento de três autores - Dewey (1976), Vygotsky (1988) e Habermas (1987) pôde-se iniciar a construção do arcabouço teórico que viesse a fornecer as pistas que nos aproximassem do conceito de aquisição da qualificação. Isso porque, para a elaboração de tal conceito teórico, não se encontrara, até então, algo já definido e sistematizado na literatura sobre qualificação. Construiu-se, então, uma abordagem multidimensional que se nutriu, em particular, daqueles três estudiosos, cujos pensamentos estão na base da maioria dos princípios educacionais modernos.

Não é de hoje (mais precisamente há cem anos) que o filósofo pragmatista J. Dewey (1976) invade e revoluciona o contexto educacional com a noção de que a aprendizagem é um continuum experiencial. Ao reconhecer os processos educacionais como reconstrução contínua da experiência, Dewey aponta a capacidade que têm os indivíduos de conferir sentido às suas experiências e de dirigir o curso das que se seguem, o que significa que o princípio da continuidade, no pensamento deweyano, concebe um modo interativo de relacionamento das pessoas entre si e com o mundo, por meio da ação, da experimentação e da experiência que

envolve toda nossa sensibilidade e modos de receber e responder a todas as condições que defrontamos na vida. Desse ponto de vista, o princípio de continuidade de experiência significa que toda e qualquer experiência toma 
algo das experiências passadas e modifica de algum modo as experiências subseqüentes. (Dewey, 1976, p. 26)

Enquanto Dewey é um legítimo representante do pensamento liberal em educação, Vygotsky $(1987 ; 1988)$ tem, na dialética materialista, sua base filosófica, o que resulta em diferenças de fundo em suas concepções de homem e de sociedade. Essas diferenças se tornam particularmente claras quando se analisa a noção de "condições objetivas” em Dewey e se as compara com o substrato do pensamento de Vygotsky. Para o primeiro, essa noção diz respeito às condições físicas e sociais, particularmente centradas no ambiente da escola; para o segundo, embora esse conceito não seja explicitado como uma categoria analítica, pode-se muito bem depreender sua filiação política de base marxista: tais condições referem-se à materialidade das contradições sociais no seu aspecto estrutural e econômico.

A noção de experiência em Dewey permite que se estabeleça uma ponte com o pensamento de Vygotsky (1987; 1988), para quem a experiência é uma aquisição de saberes que se realiza em cada situação de vida social, em que se constroem conhecimentos e habilidades correspondentes, vinculados seja à vida cotidiana, seja à investigação científica. Todavia, acentua Vygotsky (1988), cada aquisição de saber é transformação e elaboração de cultura; do que resulta, inevitavelmente, uma heterogeneidade nas formas de acesso ao saber e às habilidades, o que vem significar que a aquisição de conhecimento (na qual a memória representa um papel importante) supõe uma continuidade entre patrimônio cultural adquirido e novos saberes, entre o que é parte da memória e o que é por ela aprendido e nela fixado, posto que nenhuma aprendizagem tem o caráter de novidade absoluta - o conhecimento é sempre construção e reconstrução.

A importância da experiência, vista em Dewey e Vygotsky, por sua vez, aproxima-se do pensamento de Habermas (1987), para quem a existência social é o resultado da articulação entre o mundo da vida, coordenado por meio de interações lingüísticas, e sistema, regulado e equilibrado por meio de controle técnico e científico. Essa afirmação significa que a compreensão da ação social exige que se entenda a noção de mundo da vida como constituição da experiência; nesse sentido, são os próprios sujeitos que, em processos cooperativos de interpretação, isto é, quando buscam entender-se, fazem uso implícito do conceito de mundo. Esse ponto de vista de Habermas tem um valor teórico fundamental para a compreensão da aquisição 
da qualificação, na medida em que entende o saber e o conhecimento como um processo interativo. Tal idéia propicia a superação de certas dificuldades que as complexidades conceituais e metodológicas para o estudo da experiência como aprendizagem costumam trazer à pesquisa.

Tais conceitos permitiram que se estabelecesse uma base teórica para se compreender a aquisição da qualificação, aos quais se procurou articular as dimensões empíricas consideradas para este estudo, expressas pela: 1) educação formal - representada pelas escolas da rede de ensino, de educação geral e profissionalizante; ${ }^{1}$ 2) educação não-formal representada pelos cursos e treinamentos que, embora estruturados, não fazem parte da rede oficial de ensino; 3) educação informal representada pela educação familiar e societal em geral. Esses procedimentos buscam situar tais tipos de educação no contexto das transformações que se processam no mundo do trabalho. Para tanto, valendo-se do caráter de multidimensionalidade originalmente expresso nessa classificação, a ela se acrescentou mais um tipo de educação informal: as qualificações tácitas.

\section{O campo empírico}

A escolha por fazer de uma refinaria de petróleo o campo empírico da pesquisa deveu-se ao fato de que, dentre as indústrias de processo a Refinaria em questão: 1) é a mais antiga e que mais facilmente permite observar a convivência dos tipos de tecnologia mais e menos desenvolvidos tecnologicamente; 2) é complexa: tem um leque de produtos, atendendo a mercados diferentes e, portanto, tem unidades com conexões variadas com o mercado; 3) está hoje em intensa reestruturação, apresentando mudanças nas políticas de gestão e na filosofia, não só de pessoal, mas de gestão da produção, o que torna a percepção dos atores mais aguda; ainda por conta do processo de reestruturação, desativa unidades, fato sem precedentes na história da Refinaria.

Por ser um campo extremamente complexo, optou-se por estudar três unidades-tipo da Refinaria, doravante denominadas A, B e C. A unidade "A" é a mais nova das três selecionadas para o estudo e começou a operar em fins de 1997, atendendo, portanto, às metas estabelecidas pela empresa para a sua reestruturação, sendo, desde então, o modelo ao mesmo tempo convergente e irradiador das transformações tecnológicas para as unidades “ $\mathbf{B}$ ” e “C”. A unidade “ $\mathbf{B}$ ” deu início às operações em 1984 e a unidade "C" nasceu com a Refinaria, há mais de 50 anos. 


\section{Achados da pesquisa}

Para sistematizar os achados da pesquisa tratou-se de articular os conceitos antes desenvolvidos, com base em Dewey, Vygotsky e Habermas, de forma a se demonstrar o tratamento qualitativo e analítico das percepções dos sujeitos/trabalhadores das três unidades estudadas, por intermédio dos sentidos expressos nas suas falas, a respeito de: 1) como os trabalhadores percebem e valorizam as distintas fontes de aquisição da qualificação, vale dizer, a educação formal, não-formal e informal; 2) como a mudança organizacional e tecnológica alterou a forma de aquisição da qualificação;

3) como os trabalhadores percebem as mudanças na natureza das novas qualificações requeridas.

\section{As fontes de aquisição da qualificação e as percepções dos operadores}

Ao se dar voz aos sujeitos para que expressem visões acerca de seus percursos formativos, está-se pressupondo que, embora exista atualmente na empresa uma forte tentativa de normatização na organização do trabalho, pelo nivelamento de práticas e rotinas no cotidiano da produção, existe, em contrapartida, uma tendência à diversificação dos espaços formativos. É esse ponto que interessa verificar agora, posto que os operadores, embora venham, por um lado, se posicionando em função daquelas políticas normatizadas de gerenciamento, por outro lado, são portadores de concepções, de percepções diversas, construídas no decorrer de seus percursos formativos, seja no ambiente societal em geral (família, comunidade), seja no ambiente escolar, ou ainda nos cursos e treinamentos na Empresa, bem como no conhecimento adquirido por meio do desempenho profissional.

\section{A dimensão formal da aquisição da qualificação}

Conforme abordado anteriormente, Vygotsky (1987) chama a atenção para o fato de que a escola, por oferecer conteúdos e desenvolver modalidades de pensamento bastante específicos, tem um papel diferente e insubstituível na apropriação, pelo sujeito, da experiência culturalmente acumulada. Por esse motivo, ela representa um fator preponderante e decisivo no desenvolvimento dos indivíduos que vivem em sociedades escolarizadas, pelo fato de que promove um modo mais sofisticado de analisar e generalizar os elementos da realidade: o pensamento conceitual. Assim, vale perguntar como, onde e quando os operadores passaram pela educação escolar. 


\section{A escola regular como local de aquisição de qualificações}

Tendo em vista que o patamar médio de escolaridade dos operadores de processo da petroquímica está assentado sobre o nível médio de escolaridade, cabe agora esclarecer possíveis diferenciações entre os operadores das três unidades: se a partir do nível médio como exigência para admissão na Empresa, houve mudanças na trajetória educacional dos operadores, com a realização de cursos de nível superior; se afirmativo, que motivos levaram os operadores às novas aquisições; enfim, o que significa, para os operadores, a escolarização regular no processo de aquisição da qualificação. Dentre as falas dos operadores sobre os trajetos escolares, sobressaem alguns com percursos bastante diversificados, como um Operador II da unidade "C", que disse:

Eu comecei a estudar em Alagoinhas, de Alagoinhas eu fui até o Recife, fiz a Escola de Aprendiz de Marinheiro; eu fiz um grande curso na Marinha, lá eu não fiz só a parte teórica, mas fiz o curso profissionalizante; de volta para a Bahia, fiz vários pré-vestibulares e também fiz o curso da Escola Técnica Federal.

Indagado por que não fez o curso superior, uma vez que chegou a fazer vários concursos vestibulares, respondeu que

não deu para conciliar estudo com trabalho; na época não tinha as facilidades que se tem hoje, não tinha troca de turno, e eu tive que abandonar, no caso, as esferas do nível superior, mas não estou muito arrependido não, me dediquei ao trabalho, e hoje eu vejo a situação de me aposentar e estou pensando em voltar a estudar.

Quando instados a responder sobre qual teria sido o peso da escola na sua formação e no ingresso na carreira de operador, a maioria reflete o pensamento de um Operador I da unidade "A", que nos permite observar o papel que a escola representa como passaporte para o ingresso no trabalho:

Eu fiz o 2 grau no Colégio Estadual da Bahia, e nessa época, eu também trabalhava...; aí, comecei a fazer Matemática, na Católica, depois fiz vestibular para engenharia elétrica e acabei indo para a Escola Técnica, que naquela época, por uma questão de mercado, era a que empregava mais rápido; se você estivesse cursando a Escola Técnica ou um outro curso, como o Centec, por exemplo, era fácil arranjar um emprego...

De acordo com as informações dos sujeitos da pesquisa, a maior parte deles, à época da contratação pela empresa, havia concluído o 
nível médio (antigo segundo grau). Assim, partindo dessa informação, foi possível constatar uma significativa evolução da escolaridade desses trabalhadores. A Tabela 11 permite observar que na unidade " $A$ ", por exemplo, 14,8\% dos operadores possuem diploma de curso superior e $29,6 \%$, têm curso superior incompleto, sendo que, desses últimos, uma parte ainda estava cursando a faculdade e outra, havia desistido dos estudos. Em relação à unidade "B", 11,8\% concluíram o nível superior e 23,5\% não o concluíram. Na unidade "C", 28,6\% já são diplomados em curso superior e igual porcentagem ainda cursa uma faculdade ou desistiu de fazê-lo. Nas três unidades, os que declararam ter desistido dos estudos, na sua maioria, apontaram como causa as dificuldades para compatibilizar trabalho e estudo.

Os dados sugerem que o nível de escolaridade dos operadores da unidade "C", justamente aquela que não introduziu os mais modernos aparatos tecnológicos, é mais alto que o dos operadores das unidades “A” $\mathrm{e}$ "B”. É preciso entender o que isso poderia significar, quando se sabe que a regra nas indústrias, e o discurso gerencial o comprova, é exigir mais qualificação daqueles que trabalham com tecnologia mais avançada. Pode-se supor que o que conta para a empresa, na verdade, são os cursos e treinamentos ali realizados e não a escolarização formal, mas deve-se levar em conta que a unidade “C” não é a que apresenta maiores índices de cursos e treinamentos, como mais adiante se verá.

Com os dados que se tem, parece viável levantar uma hipótese. A maior qualificação dos operários da unidade " $C$ " pode ser explicada pela trajetória de cada um deles na empresa. De acordo com os achados anteriores, são exatamente os trabalhadores da unidade " $\mathrm{C}$ " aqueles que, embora tivessem ingressado com mais idade no trabalho (cinco, entre os sete, ingressaram já após a maioridade, diferentemente das outras unidades), na Refinaria tiveram o seu primeiro emprego. Provavelmente, essa circunstância aumentou as suas chances de investir na titulação formal, dada a maior estabilidade da trajetória ocupacional. Interessante observar, de certa forma previsível, a justificativa para a busca de qualificação pelos níveis formais de estudos. Trata-se da explicação freqüentemente ouvida durante as entrevistas, nas quais um fragmento delas resume, de forma bastante elucidativa o que representa o pensamento comum a muitos: "Estou me preparando para quando me aposentar, ou antes disso, não sei.... Quero ter uma alternativa de vida, pois sei que isso aqui pode acabar para mim, de um hora para outra... (Operador II, unidade "C")". 
Percebe-se aí um outro ponto que não poderia ficar isento de comentários. Trata-se da importância atribuída pelos operadores à aquisição de qualificações por iniciativa própria, como que representando uma "poupança" que lhes reservasse uma fatia do cada vez mais escasso bolo do mercado. Os depoimentos, ainda que deixassem transparecer um forte laço afetivo com a empresa, também traziam as marcas de um outro sentimento, algo como uma espécie de mágoa pelo fato de não poderem mais desfrutar do manto protetor da "grande mãe" e de nela estar a salvo dos sobressaltos causados pela competição, como no depoimento de um operador, para quem “(...) a gente pode até falar mal dela [a empresa] aqui entre nós, mas se surge alguma emergência, algum problema, [quanto à segurança], nós somos capazes de sair correndo e dar a vida por ela... aqui, todo mundo veste a camisa da empresa... (Operador I, unidade " $\mathrm{B}$ ")".

\section{A escolarização no ensino técnico profissionalizante}

Convém iniciar as análises sobre a aquisição da qualificação dos operadores na dimensão do ensino técnico-profissionalizante, resgatando, ainda que brevemente, um pouco da memória do período inicial da Refinaria, no que diz respeito à formação do pessoal recrutado. ${ }^{2}$ Naquele momento, início dos anos 50, inexistiam quadros técnicos formados no país, de modo que não só a construção, mas principalmente a entrada em operação e os primeiros anos de produção, foram efetivados por técnicos vindos dos Estados Unidos. Os primeiros trabalhadores selecionados pela Refinaria constituíam mão-de-obra não especializada, recrutada nas redondezas, na região agrícola do chamado Recôncavo Baiano que trabalhava sob a supervisão de técnicos americanos. Como a mão-de-obra para aquele "novo" tipo de trabalho era escassa, o trabalho intenso e a cultura do trabalho ainda por ser formada e internalizada, os trabalhadores que ali chegavam moravam na própria Refinaria, incluindo-se aí os técnicos estrangeiros.

Até 1961, ainda estavam na Refinaria muitos dos técnicos que deram partida à planta, os quais, ao passo que supervisionavam o processo de trabalho, formavam os novos quadros. Com a formação de quadros técnico-profissionais pela empresa, quando via sistema formal de ensino, começou a ocorrer a saída dos técnicos americanos e sua substituição por profissionais brasileiros. Na maioria dos casos, porém, o aprendizado era efetivado essencialmente no cotidiano do trabalho, acrescido de cursos e treinamentos oferecidos pela própria empresa. Nesses cursos, a partir do desempenho, foram surgindo aqueles que viriam a se tornar os operadores de painel e os operadores chefes das unidades então existentes (Castro, Fartes, Santos, 1998). 
A partir da década de 1970, a empresa participou ativamente da instalação do Pólo Petroquímico de Camaçari - tanto por meio da Petroquisa, subsidiária da Petrobrás no ramo químico, que era acionista de praticamente todas as empresas da primeira geração do Pólo, como fornecendo os quadros técnico-profissionais para fazer entrar em operação as plantas -, com forte contribuição da Refinaria. Cabe ressaltar o importante papel que a Empresa desempenhou, através do Cenpes, no sentido de qualificar pessoal não apenas para formar seus próprios quadros, mas para prover de mão-de-obra especializada toda a cadeia químico-petroquímica em construção naquele momento. Era o exercício de uma função social - a de formadora de recursos humanos especializados para a indústria química - que marcou o papel da empresa no cenário industrial brasileiro naquele período (idem, 1998).

Tendo essa breve referência como ponto de partida, há que se perguntar: Como se constituiu essa força de trabalho a partir dos anos de 1970? O que mudou a partir de então, até os dias de hoje, quando se sabe que o ramo químico-petroquímico está em meio a um movimento de reestruturação industrial que dá a tônica ao conjunto do parque industrial brasileiro? Acima de tudo, como vêm sendo formados os operadores para trabalhar em processos baseados no uso intensivo de automação digital e de informática, sabendo-se que, desde a partida das plantas, sua função exige uma escolaridade mais alta do que a média da escolaridade dos técnicos em indústrias tradicionais?

Um dado fundamental acerca da vivência escolar dos operadores dá conta de que perto de $80 \%$ da amostra da pesquisa realizou seus estudos de nível médio em cursos profissionalizantes, predominantemente na Escola Técnica Federal da Bahia (ETFBA, atual Cefet/BA).

Essa informação faz supor que há uma significativa influência da referida instituição de ensino sobre a formação dos operadores, o que leva a procurar resgatar o papel que ela jogou no processo de aquisição da qualificação dos operadores que lá realizaram seus estudos por, pelo menos, três anos de sua vida colegial, distribuídos entre meados de 1970/85. Ao se trazer as análises alguns dados importantes referentes à antiga Escola Técnica, por meio do reconhecimento de certas peculiaridades da Escola, no intuito de se perscrutar mais acuradamente seus egressos operadores, deparou-se com um fato bastante curioso e, ao mesmo tempo, profundamente significativo: naquele período, vivido por muitos dos operadores que hoje são sujeitos dessa pesquisa, estava em fase de consolidação um intenso processo de "reestruturação" administrativa e pedagógica, visando a dar conta das demandas da 
expansão do parque petroquímico do Estado da Bahia. Tais transformações visavam, acima de tudo, a aplicar a Lei $n^{\mathbf{a}}$ 5.692/71, de Diretrizes e Bases da Educação, desenvolvendo as habilitações profissionais em um estreito regime de cooperação com as empresas, mediante realização de convênios (LDB 5.692/71, Art. 6 6a).

A esse respeito, ajuda recorrer ao ponto de vista expresso por Habermas (1987). O prisma de análise oferecido pelos estudos desse autor, acerca do potencial da comunicação, permite agregar novos elementos de análise aos conhecimentos sobre educação profissional. Isso porque a teoria habermasiana permite entender que as relações entre a escola e o mundo do trabalho não são meramente um reflexo mecânico, tampouco completamente funcionais aos desígnios do capital. Para ele, a educação, ao articular-se com o setor produtivo, faz com que o contato com máquinas, ferramentas e equipamentos converta-se numa aproximação comunicativa com a experiência histórica do processo de produção e não seja apenas um ato técnico isolado.

As noções de "experiência”, em Dewey (1976), e de "zona de desenvolvimento proximal”, em Vygotsky (1987; 1988), articulam-se ao pensamento de Habermas e tornam-se centrais para essa compreensão. De fato, elas permitem destacar o papel da relação professor/aluno como um diálogo que não se esgota na produtividade da escola e do que já é conhecido, encontrando eco no sentido e na comunicação de saberes que se constroem de maneira compartilhada e contínua. É certo que a comunicação professor/aluno contém elementos formais do saber, mas é igualmente certo que contém atitudes inventivas que projetam novos conhecimentos adquiridos nas experiências vividas no interior da escola, na articulação teoria/prática.

\section{A dimensão não-formal da aquisição da qualificação}

Quando se observa mais de perto o que se afigura como sendo uma das grandes preocupações da Refinaria e de seus trabalhadores, parece ser, por certo, a necessidade contínua de aperfeiçoamento de sua força de trabalho. Mesmo que essa afirmativa, hoje em dia, soe como um lugar-comum, nunca se torna demasiada tal constatação. Só mesmo quem conviveu entre salas de gerências, áreas de produção, participou de cursos e treinamentos e muito conversou e observou por entre as frestas da pesquisa, no cotidiano dos almoços e dos cafezinhos no corredor, pode atestar o quanto de importância tem se revestido a aquisição contínua da qualificação, notadamente a partir da última metade dos anos 90, 
quando a Refinaria se voltou com maior intensidade para a modernização gerencial concomitantemente ao reordenamento tecnológico dos setores, nos quais antigas unidades foram desativadas (ou, estrategicamente hibernadas) e novas e modernas unidades foram criadas.

Para dar conta desse intenso movimento, desenvolveu-se toda uma política gerencial voltada para o planejamento, o desenvolvimento e a avaliação de cursos e treinamentos sistemáticos e abrangentes, articulados à área de produção, representados, localmente, pelo Setor de Recursos Humanos da Refinaria, o qual, como dito antes, está ligado ao gerenciamento central da empresa em Salvador e no Rio de Janeiro. Desse modo, importa agora perguntar: Em que se constituem as políticas de treinamento dos operadores dessas três unidades? Como os trabalhadores percebem e valorizam essa dimensão não-formal da qualificação?

\section{Do treinamento como item de seletividade à qualificação como necessidade}

Visando a uma produção qualificada com custos mais baixos, a empresa passou a adotar prática de treinamento durante o horário de serviço. Essa nova política, que vem sendo implantada desde meados de 1996, tem por mérito, segundo a gerência, transformar avaliações antes subjetivas em objetivas, negociando metas e, em função desses resultados, reorientar as atividades dos operadores. Tais propósitos gerenciais, todavia, não condizem com o que uma parte dos operadores percebe e avalia a respeito dos cursos e treinamentos, sendo bastante freqüentes as queixas voltadas aos treinamentos. Assim, quando estes são realizados fora dos horários de serviço, nos períodos de folga dos turnos (informação não mencionada pelas gerências, mas observada no decorrer da pesquisa), os operadores, de fato, demonstram descontentamento, concebendo tais ações sob um ponto de vista bastante crítico. Dizem eles que

(...) a empresa quer mostrar que se preocupa com a gente, dando todos esses cursos. Mas ela está muito é preocupada com ela mesma. Ela anota direitinho quem freqüenta e quem não freqüenta os cursos, aí, na primeira oportunidade, quando tiver que cortar, vai o que fez menos cursos... (Operador I, unidade " $\mathrm{A}$ ")

Cursos e treinamentos para as unidades podem ser realizados tanto na área da Refinaria quanto fora desta, seja no setor voltado para o gerenciamento de pessoal, situado no perímetro urbano de Salvador, seja nas próprias agências contratadas para tal. Todavia, fazendo jus à 
política de contenção de despesas, a Refinaria sempre busca, antes de alguma contratação externa, seus próprios profissionais que demonstrem possuir os conhecimentos requeridos para treinar os colegas. Tais treinamentos, sejam eles realizados por instância externa à Refinaria ou, internamente, pelos próprios operadores mais experientes, são monitorados e orientados por supervisores que registram todo o conhecimento técnico dos procedimentos aprendidos em treinamento para as periódicas checagens da ISO.

A análise sobre os treinamentos possibilitou que se observasse uma diferença entre as três unidades, com enorme desvantagem para a unidade "C", nos anos de 1998 em diante. Parece plausível supor que a unidade " $\mathrm{C}$ " (que, como se viu, possui operadores mais qualificados na educação formal, em relação às unidades "A" e "B"), destaca-se pelo esforço de autoqualificação de seus trabalhadores. No que respeita à educação formal, a Refinaria pautava-se por elevar os requisitos de ingresso e, desde cedo, nos anos 70, estabeleceu a formação técnica de nível médio como patamar mínimo. Assim, observa-se que a instituição dá o patamar de partida e os indivíduos, proativamente, atuam elevando esse patamar. Já no que respeita à educação não-formal, sua aquisição dá-se essencialmente pela via da proatividade da empresa, e esta é seletiva: beneficia os que estão na unidade mais estratégica e central a seus interesses, a unidade "A". Quanto aos tipos de cursos realizados, confirma-se que os cursos técnicos constituem a principal preocupação da Refinaria, já que, em todos os anos analisados, estão acima de $90 \%$. Há, por sua vez, um equilíbrio entre os cursos comportamentais e gerenciais.

Educação informal: relações societais e cotidiano de trabalho

\section{Relações societais}

Ao se tratar da mobilidade educacional intergeracional foi observado que a maior parte dos operadores ultrapassou o nível educacional dos pais. Estudos realizados por Guimarães (1995) e Agier \& Guimarães (1995) sobre a experiência operária na petroquímica baiana dão conta de que a maioria desses trabalhadores é oriunda de uma "pequena classe média"; são filhos de funcionários públicos ou pequenos comerciantes. É essa classe intermediária que, no decorrer dos anos de 1970, buscava na escolarização de seus filhos oportunidades de ascensão social, aproveitando-se da oferta de emprego na crescente 
indústria petrolífera da Bahia. Vale lembrar que esse período foi palco de intensas mudanças que alteraram o perfil do mercado de trabalho e das relações profissionais no estado (Agier \& Castro, 1995), com repercussões sobre o sistema de mobilidade social, de valores e representações ligados ao saber profissional. Assim, torna-se plausível supor que, muito embora o nível de escolaridade dos pais se concentrasse nos primeiros patamares da escala educacional, essa experiência fosse vivida, familiarmente, como necessidade de um projeto ascensional por meio da elevação dos padrões de escolarização familiar, realizada por intermédio dos filhos.

A quase totalidade dos operadores atribui à família de origem as "bases" de formação para o trabalho, a disciplina requerida e, principalmente, a vontade de se tornar independentes dos pais. As falas dos entrevistados confirmam essas constatações:

Minha família sempre foi pobre, meus pais lutavam com muitas dificuldades para criar seis filhos, tudo na escola pública, sabe como é...; então, a gente vê o pai lutando, a mãe lutando (a minha lavava roupa para garantir mais um dinheirinho); então você cresce vendo aquilo tudo e sente até vergonha de não lutar para melhorar; mas eu considero que o que veio da família, mesmo, foi o sustento moral; o pai não conversava, se a gente saía dos trilhos, aí vinha... (Operador II, unidade “B”).

O fator socioeconômico também desponta nas falas dos entrevistados, como um dado muito marcante na transição das trajetórias escolares para o emprego:

Fiz o primeiro grau em escola estadual pública, pois era o que meus pais podiam me dar; o segundo grau, fiz uma parte no Colégio da Polícia Militar e outra parte na Escola Técnica, curso de Eletrotécnica; saindo de lá, fiz alguns semestres de Engenharia Civil na Católica; parei porque meu rendimento escolar estava péssimo; eu diria que minha situação financeira na ocasião foi o que mais pesou na escolha da minha carreira; decidi isso quando entrei para a Escola Técnica, tendo em vista que havia grande possibilidade de encontrar emprego mais rapidamente após o curso, e foi o que aconteceu... (Operador II, unidade “C”).

\section{$A$ aquisição de qualificações tácitas: \\ $O$ cotidiano de trabalbo no chão-da-fábrica}

Trabalhar em uma indústria de refino de petróleo requer conformar-se em viver num processo contínuo. "A produção não pode 
ser interrompida, a não ser para a manutenção, nas 'paradas'”, é o que dizem os operadores que deixam para trás os 60 quilômetros que separam o centro de Salvador, onde quase todos moram, da Refinaria, para onde se dirigem nos ônibus da própria empresa, ao longo dos cinco turnos pelos quais se revezam nas suas rotinas de trabalho. O cotidiano de trabalho dos Operadores I e dos Operadores II não difere de uma unidade para outra. $\mathrm{Na}$ verdade, pode-se afirmar que a grande meta organizacional da empresa, que consiste em tornar progressivamente mais flexíveis e intercambiáveis as funções dos operadores, e que vem sendo, aos poucos, implantada, já foi viabilizada, restando somente sua completa efetivação.

Um dia de trabalho na operação começa com a chamada "passagem de turno", quando o operador vai tomar conhecimento do que está ocorrendo na sua unidade, por meio da leitura das ocorrências do turno anterior, as quais lhe transmitem informações sobre o andamento de suas respectivas unidades e do setor como um todo. No caso do Operador II, sua função é acrescida de uma parte administrativa, devendo fazer a verificação inicial do contingente que está trabalhando, isto é, se existe o mínimo necessário de quatro Operadores I trabalhando naquele turno. As instruções e recomendações são acessadas via correio eletrônico, ao qual todos os operadores estão conectados, para se inteirarem de suas tarefas mais imediatas; prática obrigatória, sem a qual o operador não consegue desenvolver atividades. Para tanto, há que ficar atento às variáveis do processo, isto é, as condições em que a unidade está operando, como temperatura, nível de pressão e vazão, além de determinar a execução de manutenção, caso haja necessidade, e observar as recomendações das normas de segurança. A partir daí, os operadores devem passar à rotina de supervisionar o processo, para verificar se este está "em linha”, isto é, se o processo está se desenvolvendo dentro das normas e procedimentos exigidos pelos padrões de qualidade desejados. Para isso, é importante que os operadores estejam, a tempos regulares, em constante ligação com o laboratório, o qual fornece os resultados das análises dos produtos.

Contudo, o correio eletrônico também supõe uma outra faceta da atividade do operador. Ele também deverá, ao longo do dia, nos momentos de "folga" (quase sempre mitigados, posto que uma das queixas dos operadores é exatamente o aperto nos horários), tomar conhecimento das estratégias mais gerais da empresa, como um todo, e da Refinaria, em particular, dentro daquilo que se convencionou 
chamar de "envolvimento" dos trabalhadores com as metas gerenciais da produção. Se a consulta ao correio eletrônico se torna indispensável à execução das tarefas diárias, tendo em vista o cumprimento das normas padronizadas pela empresa, esse mesmo correio também se torna vital ao desenvolvimento profissional e à certificação do operador, do qual se espera que esteja "em dia" com as metas e objetivos da companhia. Antes do término do turno, o Operador II deve elaborar um relatório e transmiti-lo para o coordenador de turno, atualizar a manutenção realizada, observar o que foi concluído, observar o que ficou pendente, atualizando todas essas informações no relatório para que fique registrado como a produção foi encontrada e como a está deixando para o próximo turno.

Observando-se o "chão-da-fábrica" pelo prisma dos sentidos, podese dividir o espaço de trabalho na operação em dois mundos perfeitamente distintos, embora complementares. O visitante que caminha por um desses mundos, pela chamada área da produção, sente os odores do óleo a invadirem-lhe as narinas, ouve os mais diversos ruídos, alguns ensurdecedores, provocados pelas operações físicas de compressão e descompressão de válvulas, caminha cheio de surpresas e receios, perscrutando por todos os lados e para o alto, por entre setores onde serpenteiam dutos interconectados às torres do refino, formando milhares de labirintos.

Esse é o mundo mais tangível, mais ligado aos sentidos, mais perceptível. É a "área" propriamente dita que exige, além dos requisitos básicos de conhecimentos para operar uma planta de refino de petróleo, capacidade física para abrir e fechar válvulas manualmente, se for preciso, além de muita disposição e nenhuma fobia de alturas para galgar escadas comparáveis a prédios de mais de 20 andares. Esse mundo cinzento, que se afigura quase ameaçador ao forasteiro, contrasta fortemente com um outro mundo, de cores suaves, informatizado, asséptico, acarpetado, silencioso. É o mundo do CIC. O macacão cinza e as botas, tradicionalmente utilizados na área antes descrita, está encoberto, agora, por brancos jalecos que rodeiam ilhas de computadores. A imagem futurista similar a uma nave espacial projetada pelos operadores, até o fim dos anos 80 e início dos 90 , proporcionada pelos painéis de controle do antigo sistema analógico de controle da produção, relatada por Guimarães \& Agier (1990), torna-se ainda mais forte hoje, nas representações dos operadores, após a substituição daquele tipo de controle de processo pelo SDCD, localizado na moderna instalação do Centro Integrado de Controle: 
"Isso aqui parece a Nasa!" diz um dos operadores, quando no início dos contatos, em visita de observação ao campo onde desenvolve seu trabalho nos controles informatizados.

Os sentidos do olfato e da audição, tão solicitados "na área", vêem-se, aqui, fortemente substituídos pelos da visão e do raciocínio abstrato, os quais, voltados para os coloridos monitores que reproduzem graficamente as unidades de produção, requerem a ininterrupta representação mental do fluir do processo. Assim como no tradicional processo analógico-pneumático, agora substituído pelo moderno SDCD, as atenções e as responsabilidades são elevadas, pois numa indústria de processo nada garante que este permaneça estável o tempo todo. Na verdade, a norma, propriamente, é a instabilidade, visto que "a matéria-prima, o petróleo bruto, que vem do interior da terra desde que o mundo é mundo, não vem sempre com a mesma composição, e lá embaixo [da terra] nunca foi submetida a nenhum controle de qualidade, como bem observou um dos operadores entrevistados.

Reiteradas pesquisas têm demonstrado a importância do conhecimento adquirido no chão-da-fábrica, a que os pesquisadores dão o nome de "qualificações tácitas" - entendidas como os saberes que os trabalhadores adquirem implicitamente, no decorrer de suas experiências profissionais. As percepções dos entrevistados não deixam dúvidas quanto a essa modalidade de aquisição da qualificação. De acordo com noção amplamente aceita e particularmente sublinhada por Wood \& Jones (1984), as qualificações tácitas “( ) não são necessariamente eliminadas ou ignoradas pela direção [das empresas] após a introdução de novas tecnologias, podendo, ao contrário, exercer influência vital na sua implantação". (Wood \& Jones, 1984, p. 409).

Assim, vale investigar algumas questões centrais para esse entendimento, procurando desvendar de que modo tais qualificações são adquiridas no cotidiano de trabalho dos operadores, indagando como, em contextos diferenciados das três unidades, são vivenciadas as capacidades operárias de comunicação, iniciativa e autonomia.

Vale, inicialmente, situar o cotidiano de trabalho dos operadores das unidades " $\mathrm{A}$ ", "B" e "C". É para esse dia-a-dia que convergem a maioria das experiências educativas antes analisadas e nele se desenvolvem saberes tácitos, relativas à prática produtiva. É em meio a esse ambiente onde circulam saberes adquiridos, continuamente renovados, que ocorrem as chamadas qualificações tácitas. Seus indicadores são eminentemente subjetivos, posto que o que caracteriza 
a aprendizagem no acontecendo do cotidiano de trabalho é o aprender-com-o-outro, não susceptível de mensurações e nem tampouco passível de codificações.

Por esse motivo, no intuito de obter mais clareza e sistematização no estudo a seguir, tomar-se-á de empréstimo, como categorias de análise, os quatro modelos propostos por Nonaka \& Takeuchi (1997), a eles procurando sempre articular o referencial mais amplo recolhido, principalmente, das contribuições de Dewey, Vygotsky e Habermas, por meio dos conceitos-chave desses três autores, os quais nos permitiram tecer a noção fundamental de aquisição da qualificação, como um processo multidimensional, articulado, experiencial e interativo. Esses modelos são: 1) socialização: conversão do saber tácito em saber tácito; 2) externalização: conversão do saber tácito em saber explícito; 3) combinação: conversão do saber explícito em saber explícito; 4) internalização: conversão do saber explícito em saber tácito. Para cada uma dessas categorias buscaremos alguns indicadores que emergiram como dados bastante significativos no decorrer da pesquisa de campo, no contato com o dia-a-dia dos operadores e das gerências.

\section{A conversão do conhecimento tácito em conhecimento tácito: A socialização de experiências em torno de modernas tecnologias}

A conversão do conhecimento tácito em conhecimento tácito pode ser explicada como um processo de socialização de conhecimentos a partir da troca de experiências na forma de modelos mentais ou habilidades técnicas compartilhadas. Nesse sentido, um indivíduo pode adquirir conhecimento tácito diretamente de outro sem usar a linguagem formal e articulada. A esse respeito, há uma prática bastante comum na Refinaria, facilmente observável em função da modernização tecnológica do CIC (Centro Integrado de Controle), que consiste no ensinar e aprender mútuos entre os operadores. Em volta dos consoles que gerenciam o SDCD (Sistema Digital de Controle Distribuído), como que em "ilhas", cada qual relacionada a uma unidade de operação, vêem-se dispostos grupos de operadores numa interação informal e constante, seja comunicando-se apenas pelo gesto ou pelo olhar, seja observando e imitando a prática do colega ao lado.

Em Dewey esses idéias aparecem com bastante clareza em sua obra Vida e educação (1978), quando ele diz, pelas palavras de Anísio Teixeira, seu intérprete no Brasil: 
A experiência educativa é, pois, essa experiência inteligente, em que participa o pensamento, através do qual se vêm a perceber relações e continuidades antes não percebidas.

Todas as vezes que a experiência for assim refletida, isto é, que atentarmos no antes e no depois do seu processo, a aquisição de novos conhecimentos ou conhecimentos mais extensos do que antes, será um dos seus resultados naturais. (Teixeira, 1978, p. 17)

A essas considerações sobre experiências compartilhadas em Nonaka \& Takeuchi, já presentes no pensamento de Dewey, pode-se acrescentar a contribuição de Vygotsky com sua noção da perspectiva histórica e contextualizada do processo de aprendizagem. De forma a completar o pensamento deweyano, que nos permite entender melhor o processo de aquisição das qualificações tácitas, Vygotsky acrescenta o pressuposto de que o conhecimento nasce na atividade prática dos homens, nas suas interações com os outros homens e com a natureza, por meio da demanda social, da necessidade de novos instrumentos de trabalho e de pensamento (Rego, 1995).

O papel da imitação no aprendizado, base para as experiências compartilhadas, tem igualmente em Vygotsky uma dimensão importante, na medida em que ele descarta a noção de ato puramente mecânico a essa forma de aprender. Para Vygotsky, a imitação oferece a oportunidade de reconstrução interna daquilo que o indivíduo observa externamente. Como salienta Rego (1995, p. 111), [para Vygotsky] "a imitação pode ser entendida como um dos possíveis caminhos para o aprendizado, um instrumento de compreensão do sujeito”.

\section{A conversão do conhecimento tácito em conhecimento explícito: A externalização nas políticas de gestão pelo envolvimento}

Já a forma de conversão do conhecimento tácito em conhecimento explícito pode ser observada por meio do processo de externalização, presente nas políticas de gestão da Refinaria. Esse outro exemplo, assim como o anterior, trata de uma das principais ações voltadas para a consecução da política de envolvimento dos operadores da Refinaria e desenvolve-se, periodicamente, com grupos de Operadores I e II, congregando, indistintamente, operadores das unidades "A", "B" e "C", supervisionados por um técnico de operações e por um chefe de turma. Trata-se de um programa de reuniões periódicas, em local externo ao local da operação (pode ser no Centro de Treinamento da Refinaria ou no Setor de Pessoal), durante as quais 
se discute livremente uma pauta de assuntos ligados às rotinas de trabalho, quais sejam: problemas ligados às práticas operacionais; controle e normatização dessas práticas; metas do setor de produção, além de quaisquer outras dificuldades que porventura os operadores julguem oportuno discutir.

\section{Diálogo e reflexão coletiva}

Tomando-se ainda como exemplo tais reuniões, observou-se que, nesse tipo de comunicação entre os operadores, está continuamente em curso um processo de aquisição de qualificações tácitas quando eles, para tentar conceitualizar uma imagem, expressam-na de modo articulado, por meio de palavras, na forma de metáforas, analogias, hipóteses ou modelos. E é, exatamente nesse momento, quando essas lacunas ou discrepâncias de entendimento buscam ser corrigidas por meio de exemplificações verbais, que ocorre um processo de reflexão e interação entre os operadores.

Uma forma dessa interação é o que as gerências denominam Teinamento no Local de Trabalho (TLT), normalmente ministrado pelos próprios colegas mais experientes, prática que vem sendo cada vez mais largamente difundida pela Refinaria. De fato, se se levar em conta o que dizem os operadores sobre pessoas com as quais mais aprenderam aquilo que hoje sabem de seu trabalho, bem como sobre as pessoas que eles mais ensinaram, a resposta dos entrevistados aponta sempre para colegas ou chefes mais experientes, no primeiro caso, e colegas menos preparados, no segundo. Assim, o que se pode deduzir é a existência de uma extensa rede de trocas de saberes, consubstanciados não na linguagem técnica de algum expert contratado fora dos quadros da Refinaria (embora isso não seja descartado, quando o que se busca ensinar aos operadores não dispõe de pessoal qualificado na empresa).

\section{A conversão do conhecimento explícito em conhecimento explícito: A combinação como sistematização de conceitos em um sistema de conhe- cimentos na gestão e organização do trabalho}

Para os dois autores que dão suporte metodológico a estas análises sobre a aquisição das qualificações tácitas, a combinação é um processo de sistematização de conceitos em um sistema de conhecimento, que envolve a articulação de conjuntos diferentes de conhecimentos explícitos. Para isso, os indivíduos trocam e combinam conhecimentos por 
intermédio de meios como documentos, reuniões, exposições, conversas ao telefone ou redes de comunicação computadorizadas.

Esse tipo de conversão do conhecimento ocorre quando gerentes de nível médio desmembram, decodificam e operacionalizam perspectivas da direção das empresas relativas aos negócios ou conceitos de produtos. $\mathrm{Na}$ Refinaria, esse procedimento pode ser observado num dos principais itens da rotina diária dos operadores e gerências, que consiste no uso cotidiano da rede interna de informações via computador, já mencionado anteriormente. Além do mais, dado o fato de que num setor como o de refino de petróleo, onde o raio de ação do processo de trabalho se estende por longas distâncias, separando, muitas vezes, operadores que realizam operações conjuntas, torna-se fundamental o uso constante de um aparelho pessoal de comunicação de voz, quase como um prolongamento do próprio corpo do operador.

\section{A conversãodo conhecimento explícito ao conhecimento tácito: A internalização do conhecimento pelo registro das normas e dos procedimentos}

A internalização, segundo Nonaka \& Takeuchi, é o processo de incorporação do conhecimento explícito no conhecimento tácito. Para tanto, é preciso que o conhecimento tácito acumulado seja socializado com os outros membros da organização, por meio da verbalização ou organização de conhecimentos sob a forma de documentos, manuais, normas ou procedimentos. A documentação propicia aos indivíduos internalizarem suas experiências, facilitando a transferência do conhecimento explícito pela vivência indireta das experiências alheias. Em termos objetivos, e observáveis, esse é um dos caminhos pelos quais a cultura empresarial é construída.

Um exemplo de internalização na Refinaria pode ser observado por meio dos relatórios nos quais os operadores descrevem todas as rotinas e alterações de cada turno de trabalho para o turno seguinte. Um deles é o chamado Relatório de Turno, no qual descrevem todos os procedimentos normais executados durante o turno, visando a propiciar aos operadores do turno seguinte as informações mais importantes que dêem continuidade ao processo da operação; o outro, ROA (Relatório de Ocorrências Anormais), registra os problemas ocorridos no turno, para possíveis avaliações (por parte das gerências e dos operadores, a depender da gravidade do caso), e as tomadas de decisão quanto à resolução e/ou prevenção de incidentes na operação. 
Ao transcrever suas experiências, os operadores internalizam-nas e têm a oportunidade de refletir sobre muitas de suas ações, levando o colega que lê aquele relato a experimentar, indiretamente, as experiências dos outros.

\section{Como as mudanças organizacionais alteram as formas de aquisição da qualificação}

Uma questão de fundo orientou a pesquisa acerca das percepções dos operadores quanto ao significado por eles atribuído às mudanças nas formas de aquisição da qualificação. Trata-se do significado por eles atribuído à aprendizagem no contexto atual de trabalho. A esse respeito, aparece de forma bastante nítida um dado consensual, como que um pano de fundo nas representações dos trabalhadores: tanto os operadores da unidade "A", quanto da "B" e da "C", deixaram claro em suas falas a importância da relação teoria/prática, como algo indissociável.

O substrato da importância atribuída pelos operadores à relação teoria/prática deixa entrever o conceito de habitus desenvolvido por Bourdieu (1989), segundo o qual um conjunto de condicionantes comuns em relação à atuação no cotidiano produz experiências comuns internalizadas que não cessam de agir sobre os indivíduos mesmo após o término da ação que os levou a agir de determinada forma. Em Bourdieu o habitus forma-se não apenas nos locais de trabalho, mas na vida cotidiana em geral e, principalmente, na escola.

\section{Como os trabalhadores percebem e valorizam a mudança na natureza das novas qualificações requeridas}

Da forma como atualmente é concebido o perfil almejado para os cargos nas carreiras de operador, uma série de atribuições e conhecimentos, que já eram requeridos não folmalizadamente no cotidiano de trabalho na Refinaria, passaram a ser codificados e normatizados, dando origem, em 1999, a um Manual de Descrição de Cargos, ${ }^{4}$ que pode ser melhor visualizado no Quadro a seguir. Explicitá-lo se torna importante, na medida em que permite que se avalie como as gerências identificam e hierarquizam as atribuições condizentes com o processo de reestruturação tecnológica e organizacional, e que conhecimentos são considerados importantes para o trabalho nesse novo contexto, em cada um dos campos da operação. 


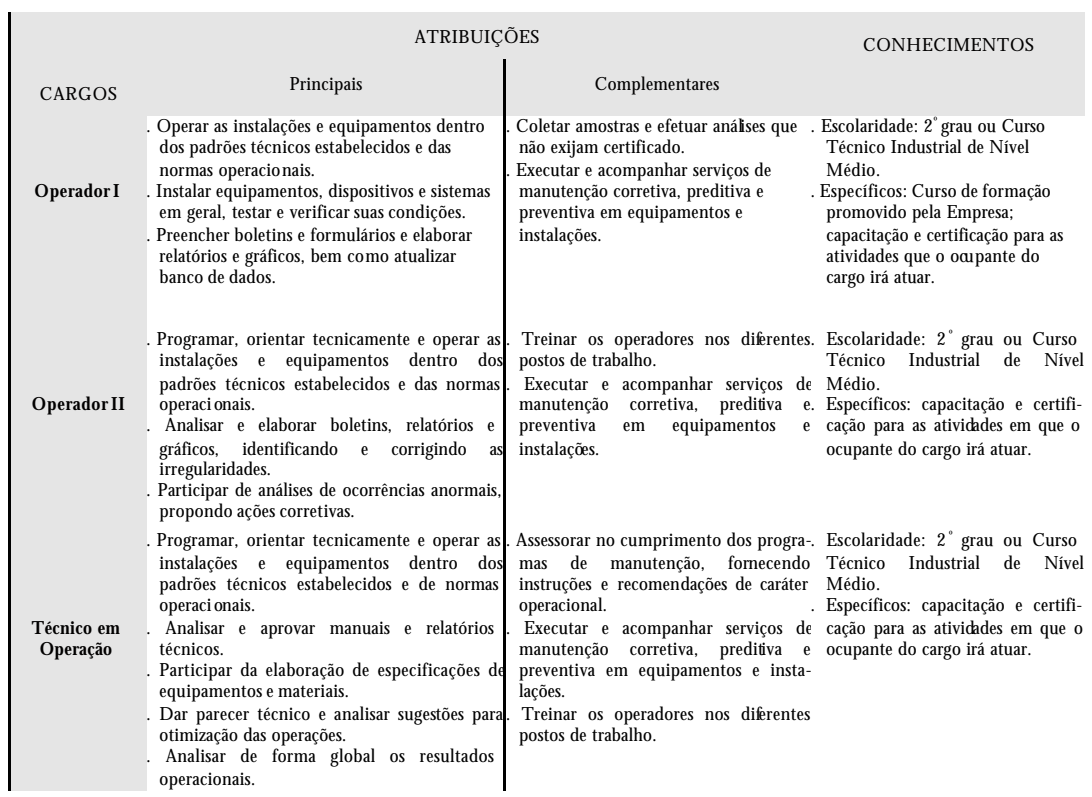

Fonte: Setor de Pessoal, Refinaria, 1999.

À luz destes dados, o que se pode dizer sobre os atuais requisitos de qualificação? O que, da sua análise, pode ser concluído sobre o processo de aquisiçãao da qualificação, num contexto em que a empresa busca adaptar-se a uma nova organização do trabalho? Observa-se no Manual um aspecto muito importante quanto às mudanças na natureza das novas qualificações requeridas. Trata-se das funções cognitivas que o documento leva a crer que devam ser mobilizadas pelos operadores. Como a operação está praticamente toda transformada pela introdução do SDCD, isso supõe trabalhar dentro de normas e padrões informatizados e digitalizados na execução de serviços de correção preditiva e preventiva. Tal atribuição leva o operador a mobilizar sua capacidade de raciocinar abstratamente, ao lidar com números e leituras de gráficos e símbolos, agora nas telas do computador e não mais nos painéis, como se fazia durante a vigência dos procedimentos de operação via painéis de controle; a exigência de instalar, testar e verificar equipamentos, por sua vez, supõe 
uma boa dose de conhecimento científico contido nos equipamentos, e como os equipamentos e a tecnologia neles contida está permanentemente se renovando, obriga o operador ao exercício contínuo da aprendizagem de novos conhecimentos e habilidades.

A exigência de um trabalhador multiqualificado salta à vista: segundo o Manual, é aos operadores de processo que cabe a maior parte da manutenção, diferentemente do que ocorria antes de a Refinaria iniciar seu processo de reestruturação, quando havia mais de um operador de manutenção para cada unidade, e ao operador não era exigida a função de cuidar da manutenção.

A análise dos requerimentos de qualificação dos operadores permite levantar a hipótese de que tais práticas, ao induzir o operador a executar tarefas até então restritas a um determinado tipo de profissional (no caso, o instrumentista), tornam o exercício profissional dotado de mais conteúdo, na medida em que não basta ao operador apenas saber operar o processo, senão também colocar os instrumentos em condições ideais de operação. Essa exigência torna o chão-da-fábrica um local privilegiado para que se possa observar o movimento contraditório que aí ocorre, onde a qualificação tradicionalmente exercida se amplia em direção a novos e contínuos saberes, forjados, entretanto, nas circunstâncias restritivas impostas pelas políticas de enxugamento da empresa.

Observa-se, também, que para exercer o cargo de Operador I e II, e de Técnico de Operações permanece a exigência do segundo grau ou curso técnico, como patamar de conhecimentos. Todavia, e isso é extremamente importante que se assinale, fica muito claro que se exigem desses profissionais mais conhecimentos que os adquiridos na escola técnica ou propedêutica -, o que, todavia, não significa que esses conhecimentos não possam ter sido parcialmente adquiridos no sistema escolar. $\mathrm{O}$ que se pretende ressaltar, na verdade, é a valorização dos conhecimentos adquiridos no decorrer do exercício do trabalho, seja por meio de cursos e treinamentos para os iniciantes, seja por meio de treinamento no posto, propiciado pelo contato e interação com os colegas mais experientes. Aliás, esse é um outro ponto a ser destacado na análise do novo Manual: a "atribuição complementar" do Operador II, de treinar os Operadores I - um dos encargos formalmente atribuídos a esse profissional na nova política de pessoal.

$\mathrm{O}$ que se pode depreender disso para o estudo sobre aquisição da qualificação? Parece que a empresa, ao tempo em que mobiliza intensamente seus esforços por qualificar os operadores, via cursos e 
treinamentos, utiliza também a política de delegar para os próprios quadros mais experientes da operação a função de treinar os iniciantes na carreira. Vale registrar que essa prática diz respeito à economia de custos que a Refinaria obtém quando repassa aos próprios colegas mais experientes a incumbência de treinar os menos experientes.

A prática de operadores mais experientes treinarem os iniciantes na carreira reforça a relação educativa entre eles, na medida em que, ao ensinar ao colega, ao interagir com o outro em situação de trabalho/ ensino/aprendizagem, novos conhecimentos são construídos. Tal construção de conhecimentos beneficia não só "quem aprende”, como igualmente aperfeiçoa e desenvolve "quem ensina", desafiado a mobilizar seu repertório de saberes previamente construídos, atualizando-o nesse processo de prática profissional/educacional. Os operadores reconhecem que o local de trabalho é seguramente onde mais aprendem e são unânimes em responder à pergunta "com quem mais aprenderam" afirmando que com os próprios colegas de trabalho.

Analiticamente, isso remete aos importantes estudos realizados por Vygotsky (1987;1988), para quem o aprender com o outro que sabe mais, ou na expressão desse autor, a interação propiciada pela "zona de desenvolvimento proximal” configura um processo que está totalmente presente nessas experiências e, igualmente, por conta desse tipo de experiência dos operadores, são todos ciosos dos conhecimentos que desenvolveram ao longo de suas experiências no trabalho.

Tal idéia pode ser complementada com desenvolvimentos do pensamento de Habermas (1987) acerca da relação entre comunicação e conhecimento profissional. A noção de "mundo da vida" por ele formulada ajuda a desvendar as estruturas e modos de interação mediados por meio da linguagem, característicos da experiência; entende-se, com Habermas, que o pano de fundo sobre o qual se desenvolvem as interações não somente se compõe de relações culturais, isto é, de padrões de interpretação, de valoração e de expressão aceitos sem questionamento, mas de habilidades interindividuais. Nesse sentido, a idéia de "mundo da vida” não só tem um caráter cognitivo, de saberes compartilhados, como também um caráter psíquico de qualificações adquiridas por meio de solidariedades socialmente creditadas.

Tais solidariedades podem muito bem ser representadas por uma experiência bastante elucidativa, que se teve a oportunidade de registrar, quando da participação da pesquisadora nas "Reuniões de Envolvimento da Divisão de Produção (Dipro) com os Setores Supervisores”. Percebeu- 
se, entre os temas tratados, que a Dipro se ressentia com o fato de que os operadores resistiam muito a cumprir as normas de procedimento operatório, tal como minudentemente cronometradas e detalhadas nos novos manuais. Ao ser-lhes solicitado material que possibilitasse melhor compreender o funcionamento da produção, tentou-se obter tais normas junto aos próprios operadores, e a reprodução do que foi dito por eles ilustra melhor os fatos:

Olha, esse papel não vai ter muito valor para você... ele [o manual de operações] não vale nada para nós; fomos nós mesmos que fizemos, quando a empresa reestruturou e os gerentes pediram que descrevêssemos o processo para eles botarem no papel e virar norma para todo mundo; foi uma discussão danada entre nós, porque ninguém queria entregar o ouro; aí, para não dar problema, a gente escreveu mais ou menos, e é por isso que ninguém cumpre direito o que está escrito, porque nós sabemos como isso foi feito ... e continuamos a operar como sempre soubemos... (Vários operadores).

A padronização dos procedimentos, também observável no episódio acima, permite reconhecer a convergência nas políticas adotadas na Refinaria, que tendem a aproximar as práticas de gerenciamento, inclusive no que diz respeito às tentativas de articular trabalho e aprendizagem no interior da produção. Há que se deixar claro, todavia, que o movimento convergente possui algumas especificidades, dentre elas poder ser observado entre as partes de uma mesma instituição, como é o caso aqui estudado, que vê se tornarem progressivamente mais similares os espaços internos de uma instituição complexa e de longa trajetória, orientados por um novo modelo de cultura normativa (Castro, 1996). Tal fenômeno, provavelmente, seria diverso, se não se tivesse escolhido comparar unidades dentro de uma mesma empresa, diversa e longeva, mas entre empresas dentro de uma mesma cadeia. Diz-se isso porque a força atual dos estudos sobre cadeias produtivas dá conta de que a posição das empresas na cadeia produtiva, assim como a relação que se estabelece entre os vários elos da cadeia (as relações interfirmas), interfere no padrão de utilização do trabalho por meio de diferentes lógicas oriundas da importância do item produzido para a garantia do produto final. A esse propósito, o estudo de Leite \& Rizek (1998) é bastante esclarecedor. Investigando a temática da qualificação a partir da análise das relações interfirmas na cadeia automotiva e no complexo petroquímico brasileiro, as autoras apontaram a presença simultânea de tendências à qualificação e desqualificação da força de trabalho nos diferentes pontos da cadeia e do complexo, como faces de uma mesma moeda, que se complementam e retroalimentam. 
Conquanto exista um caráter articulador nas experiências de educação no local de trabalho, fruto das políticas mais amplas de integração no gerenciamento, parece plausível supor que exista simultaneamente um caráter diversificador nos percursos formativos dos trabalhadores, que faz a aprendizagem migrar - com maior ênfase após a reestruturação - da escola para os locais onde se vai efetivamente exercer a profissão. Essa realidade se expressa na força crescente dos cursos e treinamentos nos espaços internos da instituição, bem como na valorização que gerências e operadores conferem às experiências de aprendizagem mútuas entre os trabalhadores, durante o exercício do trabalho.

\section{Considerações finais}

Merece registro algo de muito importante que ocorreu no desenvolvimento da pesquisa. A idéia central que fundamentava uma análise comparativa entre unidades com idades tecnológicas diferentes, e que, por isso mesmo, haveria de exibir modos diferenciados de gestão do trabalho, foi, no decorrer da investigação de campo, pouco a pouco substituída pela noção de que existe um duplo movimento que preside o modelo paradigmático das mudanças tecnológicas e organizacionais naquele contexto investigado, vale dizer, no contexto interno de uma mesma instituição.

Um dos movimentos, de natureza convergente, expressou-se pelas normas de organização do trabalho, que, ao mesmo tempo em que busca tornar sistêmicos e homogêneos os procedimentos gerenciais, faz emergir um caráter divergente/diversificador na aquisição da qualificação, expressando-se nos percursos formativos dos trabalhadores. Isso resulta em que o gerenciamento interno da instituição, ao se mover em direção a um só modelo de incorporação e utilização do trabalho, minimizando diferenças intra-institucionais, simultaneamente maximiza distinções intra-individuais, no que diz respeito às qualidades, trajetos educacionais e espaços formativos dos trabalhadores. Tais como forças complementares, ao tempo em que agem centripetamente, aproximando tendências no gerenciamento interno da empresa, atuam centrifugamente, diversificando e valorizando as fontes de aquisição da qualificação, tornando-as múltiplas.

Recebido em março de 2001.

Reformulado pela autora em janeiro de 2002.

Aprovado em fevereiro de 2002. 


\section{Notas}

1. Para efeito dessa pesquisa, foram consideradas apenas as Escolas Técnicas Federais como espaços de educação profissional, levando-se em conta que a quase totalidade dos sujeitos dessa pesquisa realizou seus estudos de "segundo grau" nessa instituição e que, dentre a multiplicidade de escolas, cursos e treinamentos existentes no País, as Escolas Técnicas Federais operam em bases formais, oferecendo cursos e diplomas regulados pela LDB.

2. Em 1953, quando a empresa foi criada, a Refinaria já operava desde 1950, com a produção de $400 \mathrm{~m}^{3}$ por dia, e com apenas uma unidade de destilação. O projeto foi de autoria da empresa americana M. W. Kellog, que participou da sua construção.

3. Foi exatamente esse o termo utilizado pela ETFBA, há mais de 20 anos, como que se antecipando às profundas transformações hoje largamente conhecidas como "reestruturação produtiva"; a origem dessa expressão se encontra no documento "Reestruturação", do qual emanavam as diretrizes para as mudanças administrativas e pedagógicas na instituição. Mais detalhes sobre essa fase vivida pela antiga Escola Técnica Federal da Bahia podem ser encontrados na pesquisa de Vera L. Bueno Fartes, Modernização tecnológica e formação dos coletivos fabris: Um estudo na Escola Técnica Federal da Bahia, dissertação de mestrado, Faced/UFBA, 1994.

4. Manual de Descrição de Cargos, 1999.

Referências bibliográficas

AGIER, Michel; CASTRO, Nadya A. "Projeto operário, projetos de operários”. In: Imagens e identidades do trabalho. São Paulo: Hucitec, 1995.

. ; GUIMARÃES, Antonio S. A. "Técnicos e peões: A identidade ambígua”. In: Imagens e identidades do trabalho. São Paulo: Hucitec, 1995.

BOURDIEU, Pierre. O poder simbólico. Lisboa: Difel, 1989.

BRANDÃO, Carlos R. O que é educação. 21ํe. edão Paulo: Brasiliense, 1988.

CASTRO, Nadya A.; FARTES, Vera L. Bueno; SANTOS, Martha Mo R.R. dos. O primeiro elo da cadeia: Reorganização e monopólio (a experiência da Refinaria). In: Qualificação, mercados e processos de trabalho: estudo comparativo no complexo químico brasileiro. Programa de Pesquisa em Ciência e Tecnologia, Qualificação e Produção. Cedes/Finep/PDCT-CNPq. Relatório Final. São Paulo, 1998.

CASTRO, A. Nadya; GUIMARÃES, A. Sérgio. Competitividade, tecnologia e gestão do trabalho: A petroquímica brasileira nos anos 90. Seminário Temático Tecnologia, Cultura e Organização na Indústria Brasileira, Anpocs, Caxambu (MG), 1990. 
Além de Braverman, depois de Burawoy: Novas vertentes analíticas na Sociologia do Trabalho. Revista Brasileira de Ciências Sociais, Anpocs/Dumara, 1991, nª 17.

CASTRO, Nadya. "Organização do trabalho, qualificação e controle na indústria moderna”. In: MACHADO, Lucília R. de S. et al., Trabalho e educaşão. Campinas: Papirus; Ande/Anped, 1992.

Qualificação, qualidades e classificações. Educaşão \& Sociedade, Campinas: Cedes, 1993, nª 45.

A fabricação de um novo consenso: Reestruturando a produção e as relações industriais (estudo de caso na petroquímica brasileira). Projeto Universität Brenen - Cebrap, Transformación Económica e Trabajo en América Latina. São Paulo, 1996 (mimeo).

DEWEY, J. Experiência e educação. Tradução por Anísio Teixeira. São Paulo: Nacional, 1976.

DRUCKER, Peter F. Sociedade pós-capitalista. São Paulo: Pioneira, 1993.

GUIMARÃES, Antônio Sérgio A. Organização e gestão do trabalho na petroquímica. Bahia: Universidade Federal da Bahia, CRH, 1987.

" "A ilusão do atalho: a experiência operária da pequena burguesia em descenso". In: Imagens e identidades do trabalho. São Paulo: Hucitec/Orstom, 1995.

HABERMAS, J. "Trabalho e interação". In: Técnica e ciência como ideologia. Lisboa: Setenta, 1987.

LEITE, Marcia de Paula. O futuro do trabalbo: Novas tecnologias e subjetividade operária. São Paulo: Scritta/Fapesp, 1994.

.; POSTHUMA, Anne Caroline. Reestruturação produtiva e qualificação: Reflexões iniciais. Projeto Cedes/Finep/CNPq. Campinas, 1995 (mimeo).

.; RIZEK, Cibele S. (Orgs.) "Cadeias, complexos e qualificações”. In: LeITE, Marcia P. \& Neves, Magda A. Trabalbo, qualificação e formação profissional. São Paulo; Rio de Janeiro: Alast, 1998.

NONAKA, Ikujiro; TAKEUCHI, Hirotaka. Criação de conhecimento na empresa: Como as empresas japonesas geram a dinâmica da inovação. Rio de Janeiro: Campus, 1997. 
REGO, Teresa Cristina. Vygotsky, uma perspectiva histórico-cultural da educação. Petrópolis: Vozes, 1995.

TEIXEIRA, Francisco Lima C. Notas sobre os impactos de mudanças gerenciais e tecnológicas na força de trabalho da indústria química baiana. Força de Trabalho e Emprego, Salvador: Coordenação Adjunta de Informações do Trabalho/Coordenação de Relações do Trabalho, 1992, n⿳⺈ 2/3.

VYGOTSTY, Lev S. A formação social da mente. São Paulo: Martins Fontes, 1987.

. Pensamento e linguagem. São Paulo: Martins Fontes, 1988. 